\title{
ENDOVASCULAR TREATMENT OF IATROGENIC CENTRAL VEIN STENOSIS AND OCCLUSION IN PATIENTS UNDERGOING HAEMODIALYSIS - A TWO-YEAR FOLLOW-UP
}

\author{
Paweł Maga', Jolanta K. Kościelniak², Paweł Kaczmarczyk², Marek Krzanowski², \\ Andrzej Belowski², Łukasz Partyka², Paweł Kucziaª ${ }^{3}$ Rafał Niżankowski ${ }^{1}$ \\ 'Department of Angiology, ${ }^{\text {nd }}$ Chair of Internal Medicine, Jagiellonian University Medical \\ College, Krakow, Poland \\ ${ }^{2}$ Angiomed, Krakow, Poland \\ 3Jagiellonian University Medical College, Krakow, Poland
}

\author{
ORIGINAL PAPER \\ Phlebological Review 2016; 24, 2-3: 46-49 \\ DOl: https://doi.org/10.5114/pr.2016.65519 \\ Submitted: 11.08 .2016 \\ Accepted: 8.11.2016
}

\section{ADDRESS FOR CORRESPONDENCE}

Jolanta K. Kościelniak

Department of Angiology

Angiomed

Skawinska 8, 31-066 Krakow

Poland

e-mail: aajolek28@gmail.com

and 39 occlusions). Percutaneous transluminal angioplasty (PTA) or percutaneous transluminal angioplasty with stenting (PTS) was committed. There was no randomisation. Stent implantation was avoided in vessels with a foreign body inside (catheter or electrode). Diagnostic phlebographies were performed after 12 and 24 months or if symptoms recurred. The follow-up period lasted for 24 months. There were 26 (70\%) patients with primary stenosis and $11(29 \%)$ with occlusion in the group with PTA therapy and $13(38 \%)$ and $21(61 \%)$ in the group with PTS therapy. Procedure was successful in all cases of stenosis, unsuccessful in 10 cases of occlusions. Seventeen patients died during first year of observation, 9 during the second. Two patients were lost to follow up. No serious adverse events were observed.

Results: Primary patency (PP) after 12 and 24 months was 50\% and 26\% after PTS, $33 \%$ and $21 \%$ after PTA respectively. Primary assisted patency (PAP) was $70 \%$ and $52 \%$ in PTS group while $86 \%$ and $92 \%$ in PTA group. Secondary patency (SP) $70 \%$ and $52 \%$ after PTS to $93 \%$ and $92 \%$ after PTA.

Conclusions: Both methods are safe and mildly effective in the treatment of central veins in haemodialysis patients. Both techniques should be applicable in specific clinical settings according to patient status and operator experience.

Key words: haemodialysis, stenting, balloon angioplasty, endovascular treatment, central vein.

\section{INTRODUCTION}

Central venous occlusive disease (CVOD) is a common and growing problem in the long-term management of vascular access patency in patients undergoing haemodialysis. Additionally, the number of dialysis patients is also increasing, and up to $50 \%$ of them will experience CVOD after haemodialysis catheter use [1]. However, more than half of them may experience symptomatic resolution after removal of the dialysis catheter, obviating the need for invasive treatment [2]. Following catheter removal, $28 \%$ of all patients have radiological evidence of central vein stenosis (CVS) persisting beyond three months [3]. In symptomatically refractory cases, inter- vention is required. Percutaneous transluminal angioplasty (PTA), occasionally accompanied by stenting (PTS), is accepted as the initial intervention for patients with CVOD [4].

The objective of our report was to evaluate the results of endovascular CVOD treatment in patients with haemodialysis shunts.

\section{MATERIAL AND METHODS}

Eighty-one consecutive patients with CVOD referred for treatment in our tertiary interventional centre were included into the study group. 
The inclusion criteria were: 1) clinically significant shunt dysfunction and/or 2) limb oedema. Lesions were characterised at baseline by the type (stenosis versus occlusion), location, segmental length, and diameter of stenosis (where applicable). Patients were treated with PTA or PTS whenever essential. There was no randomisation, and the decision for stent implantation (i.e. PTS) was based on two criteria: 1) residual, post-angioplasty stenosis $\geq 60 \%$ and/or 2 ) persistent collaterals. The follow-up period lasted for 24 months. The results of follow-up phlebography performed at 12 and 24 months after endovascular treatment were categorised as: stenosis $<50 \%$, stenosis $>50 \%$, or occlusion. The results were then compared according to the method of treatment: PTA versus PTS. The outcomes were: primary, primary assisted, and secondary patency rates, respectively. The primary patency (PP) was defined as the vessel patency without any re-intervention, secondary patency (SP) as the vessel patency achieved with additional intervention or multiple interventions due to vessel occlusion, while primary assisted patency (PAP) was defined as patency achieved with additional intervention or multiple interventions due to vessel restenosis [5]. The data were analysed retrospectively.

SPSS package (SPSS Inc. Released 2009. PASW Statistics for Windows, Version 18.0. Chicago: SPSS Inc.) was used to evaluate variables in descriptive statistics and Fisher's exact test. Data were also analysed in respective contingency tables. Barnard's exact test was also used to assess statistical differences using $\mathrm{R}$ exact package (Calhoun P [2015]. Unconditional Exact Test. $\mathrm{R}$ package version 1.6).

\section{RESULTS}

A total of 81 haemodialysis patients (47 males and 34 females; mean age: $64.5 \pm 13.0$ years) with stenotic or occlusive lesions were treated in our study (Table 1). There were 81 lesions treated (42 stenosis and 39 occlusions). There were $26(70 \%)$ patients with primary stenosis and $11(29 \%)$ with occlusion in the group with PTA therapy and $13(38 \%)$ with stenosis and $21(61 \%)$ in the group with PTS therapy. The procedure was successful in all cases of stenosis but unsuccessful in 10 cases in occlusion group. Those 10 casews were excluded from further follow up. Seventeen patients died (cause not related to procedure) during the first year of observation, and nine during the second year. Two patients were lost to follow-up. No serious adverse events were observed.

The mean initial lesion stenosis was $86.5 \%$ (range: $60-95 \%$ ) with segmental lesion length of $25.3 \mathrm{~mm}$ in the PTA group, and $82 \%$ (range: $65-95 \%$ ) with 28.3 mm-lesion lenght in the PTS group, respectively. No significant differences regarding the location of lesions in the patients' body side were found between the two groups.
The results of diagnostic phlebographies are shown in Table 2.

The differences in the number of occluded vessels on the left and right sides of the body were also observed. Venous occlusions appeared to be more frequent on the right side of the body at 12 months (Table 3 ). No serious adverse events such as death, myocardial infarction (MI), stroke, or serious bleeding caused by vessel rupture were observed. No stent migration, stent fracture, or signifi-

Table 1. Patients' characteristics

\begin{tabular}{lc}
\hline \multicolumn{1}{c}{ Patient characteristic } & $\begin{array}{c}\text { Number of patients, } \\
\boldsymbol{n} \text { (total } \mathbf{~} \mathbf{8 1} \text { ) }\end{array}$ \\
\hline Male & 47 \\
\hline Mean age \pm SD (years) & $64.2 \pm 13.1$ \\
\hline Coronary heart disease (CHD) & 41 \\
\hline Peripheral artery occlusive disease (PAOD) & 9 \\
\hline Hypertension (HTN) & 59 \\
\hline Congestive heart failure (CHF) & 12 \\
\hline Stroke/transient ischemic attack (TIA) & 9 \\
\hline Diabetes mellitus (DM) & 31 \\
\hline Smoking & 17 \\
\hline Chronic obstructive pulmonary disease (COPD) & 5 \\
\hline
\end{tabular}

Table 2. Results of diagnostic phlebographies at 12 and 24 months

\begin{tabular}{lcc}
\hline & Stenotic group (StG) & Occlusive group (OcG) \\
\hline 12-month result & & Total = 54 \\
\hline & $n=31$ & $n=23$ \\
\hline Stenosis < 50\% [n(\%)] & $24(77.4 \%)$ & $10(43.4 \%)$ \\
\hline Occlusion $[n(\%)]$ & $1(3.22 \%)$ & $8(34.7 \%)$ \\
\hline Stenosis > 50\% [n (\%)] & $6(19.3 \%)$ & $5(21.7 \%)$ \\
\hline 24-month result & & Total $=43$ \\
\hline Stenosis < 50\% [n(\%)] & $16(66.6 \%)$ & $n=19$ \\
\hline Occlusion $[n(\%)]$ & $2(8.3 \%)$ & $7(36.8 \%)$ \\
\hline Stenosis > 50\% $[n(\%)]$ & $6(25 \%)$ & $9(47.3 \%)$ \\
\hline
\end{tabular}

Table 3. Lesion location

\begin{tabular}{lc}
\hline Location of lesion(s) & Number of interventions, $\boldsymbol{n}$ (total = 81) \\
\hline Right-side & $40(31.5 \%)$ \\
\hline Left-side & $37(29.9 \%)$ \\
\hline Superior vena cava (SCV) & $3(2.4 \%)$ \\
\hline SVC and right-side & $2(1.62 \%)$ \\
\hline
\end{tabular}


Table 4. Number of reinterventions at 12 and 24 months

\begin{tabular}{lcccc}
\hline & \multicolumn{4}{c}{ Number of reinterventions } \\
\cline { 2 - 5 } & \multicolumn{3}{c}{ After PTA } & After PTS \\
\hline Observation period & $\mathbf{0 - 1 2}$ months & $12-24$ months & $\mathbf{0 - 1 2}$ months & $12-24$ months \\
\hline Stenotic group (StG) & 17 & 8 & 2 & 1 \\
\hline Occlusive group (OcG) & 7 & 2 & 9 & 5 \\
\hline
\end{tabular}

PTA - percutaneous transluminal angioplasty; PTS - percutaneous transluminal angioplasty with stenting

Table 5. Patency results at 12 and 24 months

\begin{tabular}{lcccc}
\hline & \multicolumn{2}{c}{ PTA group } & \multicolumn{2}{c}{ PTS group } \\
\hline Observation period & $\begin{array}{c}0-12 \\
\text { months }\end{array}$ & $\begin{array}{c}12-24 \\
\text { months }\end{array}$ & $\begin{array}{c}\mathbf{0}-12 \\
\text { months }\end{array}$ & $\begin{array}{c}12-24 \\
\text { months }\end{array}$ \\
\hline $\begin{array}{l}\text { Primary patency } \\
\text { (PP) rate (\%) }\end{array}$ & 33.0 & 21.0 & 50.0 & 26.0 \\
\hline $\begin{array}{l}\text { Secondary patency } \\
\text { (SP) rate (\%) }\end{array}$ & 93.0 & 92.0 & 70.0 & 52.0 \\
\hline $\begin{array}{l}\text { Primary assisted } \\
\text { patency (PAP) } \\
\text { rate (\%) }\end{array}$ & 86.0 & 92.0 & 70.0 & 52.00 \\
\hline $\begin{array}{l}\text { PTA - percutaneous transluminal angioplasty; PTS - percutaneous transluminal } \\
\text { angioplasty with stenting }\end{array}$ & & & & \\
\end{tabular}

cant stent shortening immediately, or several weeks or months after the insertion, were seen.

During the first 12 months of follow-up, a total of 35 re-interventions were performed, and in the period between 12 and 24 months there were 17 (Table 4).

The results of patency rates at both 12 and 24 months demonstrated a higher PP rate in the PTS group (50\% and $26 \%$ ) than in the PTA group (33\% to 21\%). Primary assisted patency (PAP) rates presented a prevalence in the PTA group of $86 \%$ and $92 \%$ to $70 \%$ and $52 \%$, in the PTS group. Secondary patency also showed higher rates in the PTA group $93 \%$ and $92 \%$ to $70 \%$ and $52 \%$ in PTS group (Table 5).

\section{DISCUSSION}

Endovascular treatment is currently the mainstay of care in patients with CVOD. The treatment options include PTA, PTS, and placement of covered stents. Before the development of endovascular techniques, open surgical treatment was the only management strategy. Although surgical treatment of CVS is effective (PP rate of $80-85 \%$ at 1 year) [6], it has significant limitations due to high surgical morbidity (especially among patients with stenosis in the thoracic region) and overall poor general condition of haemodialysis patients [7]. On the contrary, the endovascular technique is a less invasive treatment modality for CVS. Questions arise, however, concerning the durability and efficacy of angioplasty in the treatment of CVS. There are numerous studies that apply different methods of endovascular CVOD treatment [8-10]. However, most of them are small, uncontrolled, single institution studies. As such, the data reported in these studies for angioplasty alone are usually not sufficient to merit recommendation. The PP rates for PTA are reportedly between $28 \%$ [11] and 55\% [9] at six months and between 9\% [12] and 29\% [10] at 12 months. Percutaneous transluminal angioplasty is associated with a better success rate than PTA, but there is a lack of reliable randomised trials. Additionally, stents may break, migrate, or shorten during deployment. Stent placement may also preclude future endovascular procedures or surgical revisions and could incite intimal hyperplasia leading to recurrent stenosis and multiple re-interventions. The PP rates for PTS technique range from 33\% [13] to $68 \%$ [14] at six months and from $19 \%$ [13] to $21 \%$ [10] at 12 months.

Our study presents data that are consistent with numerous previous reports on the subject, thus demonstrating the safety and efficacy of endovascular techniques in CVOD $[10,15]$.

Percutaneous transluminal angioplasty technique was used in more difficult and more demanding cases (mainly venous occlusions) and mostly when a satisfactory result was not achieved with PTA alone, rarely as a first choice treatment. In our study there was no randomisation or matched control group. Thus it is not possible (nor was it our intention) to compare directly those methods.

\section{CONCLUSIONS}

Our 24-month observation indicates that both PTA and PTS are safe methods of treatment for central vein stenosis and occlusions. Both provide moderately good results in relation to vessel patency, as well as with multiple additional interventions. Especially high rates of restenosis and re-occlusions during first year of observation lead to the conclusion that patients after treatment should be controlled more frequent in that period (phlebography, for example, at 3, 6, and 12 months after the procedure). 
The authors declare no conflict of interest.

\section{References}

1. Agarwal A.K., Patel B.M., Haddad N.J. Central vein stenosis: a nephrologist's perspective. Semin Dial 2007; 20: 53-62.

2. Rice T.W., Rodriguez R.M., Light R.W. The superior vena cava syndrome: clinical characteristics and evolving etiology. Medicine (Baltimore) 2006; 85: 37-42.

3. Hernández D., Díaz F., Rufino M., Lorenzo V., Pérez T., Rodríguez A., De Bonis E., Losada M., González-Posada J.M., Torres A. Subclavian vascular access stenosis in dialysis patients: natural history and risk factors. J Am Soc Nephrol 1998; 9: 1507-1510.

4. Vascular Access Work Group. Clinical practice guidelines for vascular access. Am J Kidney Dis 2006; 48 Suppl 1: S248-S273.

5. Zeller T. Current state of endovascular treatment of femoro-popliteal artery disease. Vasc Med 2007; 12: 223-234.

6. Bhatia D.S., Money S.R., Ochsner J.L., Crockett D.E., Chatman D., Dharamsey S.A., Mulingtapang R.F., Shaw D., Ramee S.R. Comparison of surgical bypass and percutaneous balloon dilatation with primary stent placement in the treatment of central venous obstruction in the dialysis patients: One-year follow-up. Ann Vasc Surg 1996; 10: 452-455.

7. Kundu S. Review of central venous disease in hemodialysis patients. J Vasc Interv Radiol 2010; 21: 963-968.

8. Sprouse L.R. 2nd, Lesar C.J., Meier G.H. 3rd, Parent F.N., Demasi R.J., Gayle R.G., Marcinzyck M.J., Glickman M.H., Shah R.M., McEnroe C.S., Fogle M.A., Stokes G.K., Colonna J.O. Percutaneous treatment of symptomatic central venous stenosis. J Vasc Surg 2004; 39: 578-582.

9. Surowiec S.M., Fegley A.J., Tanski W.J., Sivamurthy N., Illig K.A., Lee D.E., Waldman D.L., Green R.M., Davies M.G. Endovascular management of central venous stenoses in the hemodialysis patient: results of percutaneous therapy. Vasc Endovascular Surg 2004; 38: 349-354.

10. Bakken A.M., Protack C.D., Saad W.E., Lee D.E., Waldman D.L., Davies M.G. Long-term outcomes of primary angioplasty and primary stenting of central venous stenosis in hemodialysis patients. J Vasc Surg 2007; 45: 776-783.

11. Beathard G.A. Percutaneous transvenous angioplasty in the treatment of vascular access stenosis. Kidney Int 1992; 42: 13901397.

12. Asif A., Salman L., Carrillo R.G., Garisto J.D., Lopera G., Barakat U., Lenz O., Yevzlin A., Agarwal A., Gadalean F., Sachdeva B., Vachharajani T.J., Wu S., Maya I.D., Abreo K. Patency rates for angioplasty in the treatment of pacemaker-induced central venous stenosis in hemodialysis patients: results of a multi-center study. Semin Dial 2009; 22: 671-676.

13. Maya I.D., Saddekni S., Allon M. Treatment of refractory central vein stenosis in hemodialysis patients with stents. Semin Dial 2007; 20: 78-82.

14. Chen C.Y., Liang H.L., Pan H.B., Chung H.M., Chen W.L., Fang H.C., Lo A., Chen C.K., Lai P.H., Yang C.F. Metallic stenting for treatment of central venous obstruction in hemodialysis patients. J Chin Med Assoc 2003; 66: 166-172.

15. Quinn S.F., Schuman E.S., Demlow T.A., Standage B.A., Ragsdale J.W., Green G.S., Sheley R.C. Percutaneous transluminal angio-plasty versus endovascular stent placement in the treatment of venous stenoses in patients undergoing hemodialysis: Intermediate results. J Vasc Interv Radiol 1995; 6: 851-855. 